\title{
A Lignosulfonate Binder for Hard Carbon Anodes in Sodium-Ion Batteries: A Comparative Study
}

\author{
Ritambhara Gond, Habtom Desta Asfaw, Omid Hosseinaei, Kristina Edström, Reza Younesi, \\ and Andrew J. Naylor*
}

Cite This: ACS Sustainable Chem. Eng. 2021, 9, 12708-12717

Read Online

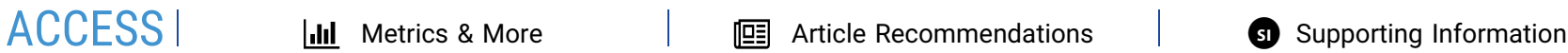

ABSTRACT: An important factor in the development of sodium-ion batteries (SIBs) is the use of cheap and sustainable materials. Sodium lignosulfonate, a lignin derivative, is demonstrated here as an attractive, "green", water-soluble, and potentially cost-effective binder for use in hard carbon anodes for SIBs. A comparison of its battery cycling performance is made against other binders including sodium carboxymethyl cellulose and lignin, obtained from the kraft process, as well as sodium alginate, derived from algae. Apart from lignin, which requires processing in $\mathrm{N}$-methyl-2-pyrrolidone, the other three binders are water-soluble. Lignosulfonate

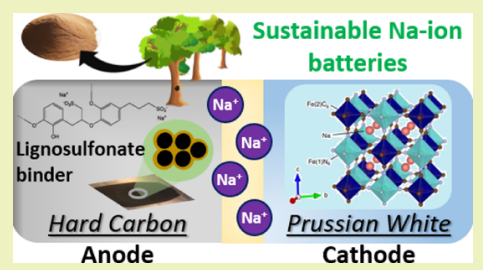
shows comparable or better performance, with high capacity retention and stability, when using $1 \mathrm{M} \mathrm{NaPF}_{6}$ in propylene carbonate or ethylene carbonate:diethyl carbonate electrolytes for both half- and full-cells (against a Prussian white cathode). Further improvements are observed when including styrene-butadiene rubber as a co-binder. X-ray photoelectron spectroscopy demonstrates similar solid electrolyte interphase compositions after the initial sodium insertion for both lignosulfonate and carboxymethyl cellulose binders. However, after subsequent cycling, the surface layer composition and thickness are found to be dependent on the binder. For the lignosulfonate-based electrode, the layer appears thicker but comprises a smaller fraction of carbon-oxygen species.

KEYWORDS: sodium-ion battery, hard carbon, sustainable binders, lignosulfonate, X-ray photoelectron spectroscopy

\section{INTRODUCTION}

Recent advances in electrode fabrication and processing have shown that biopolymers can function as environmentally friendly and inexpensive binders for lithium-ion (LIB) and sodium-ion battery (SIB) composite electrodes. ${ }^{1-3}$ Particularly, water-processable cellulose derivatives have become competitive replacements for fluorinated polymers, which are known to be persistent environmental pollutants. One abundant natural polymer is lignin. Kraft lignin, a byproduct from pulp mills, has previously been reported as an inexpensive and environmentally friendly binder in LIBs. ${ }^{2,4,5}$ However, its insolubility in water places lignin at a disadvantage since it requires $\mathrm{N}$-methyl-2-pyrrolidone (NMP), a hazardous and teratogenic solvent, for electrode formulation. The use of naturally available and water-soluble binders can help protect the environment and promote sustainable methods of electrochemical energy storage. ${ }^{1,6,7}$ The sulfonated lignin derivative, sodium lignosulfonate ("LgSA"), offers both nontoxicity and water solubility, positioning it as a potentially sustainable binder to be used for SIBs.

Recently, SIBs have gained interest for their potential use in stationary energy storage solutions as sodium-containing resources are more abundant than lithium on earth. ${ }^{8-11}$ There are numerous types of cathode materials used for SIBs, often analogous to those found in LIBs, for example, layered transition metal oxides, polyanionic materials, organic materials, and Prussian blue analogues (PBAs). ${ }^{12-14}$ Prussian white $\left(\mathrm{Na}_{2-x} \mathrm{Fe}\left[\mathrm{Fe}(\mathrm{CN})_{6}\right]\right.$ with small $\left.x\right)$ is one such PBA, which offers high performance, is composed of abundant elements, and can be synthesized at a low cost. ${ }^{15} \mathrm{~A}$ range of active materials has been studied as negative electrodes in SIBs, of which non-graphitized carbons, known as hard carbons, are considered as the most promising for application in commercial SIBs. ${ }^{16-20}$ Aside from its unique structure, which is determined by synthesis conditions, the electrochemical performance of hard carbon is impacted by the choice of electrolytes and electrode binders. ${ }^{21-25}$

With respect to the choice of binder, it has been shown that graphitic electrodes made with water-soluble binders show more uniform distribution of the active material and binder when compared with non-aqueous binders. ${ }^{26,27}$ The kinetics of the drying process plays a crucial role in the homogeneity of components in the dried electrode. In addition, the binder can significantly influence the mechanical integrity of electrodes, adhesion, resistance, cycle life, and solid electrolyte interphase (SEI) layer formation. ${ }^{1,3,22,28-37}$ Therefore, particular attention

Received: August 3, 2021

Revised: August 24, 2021

Published: September 2, 2021 

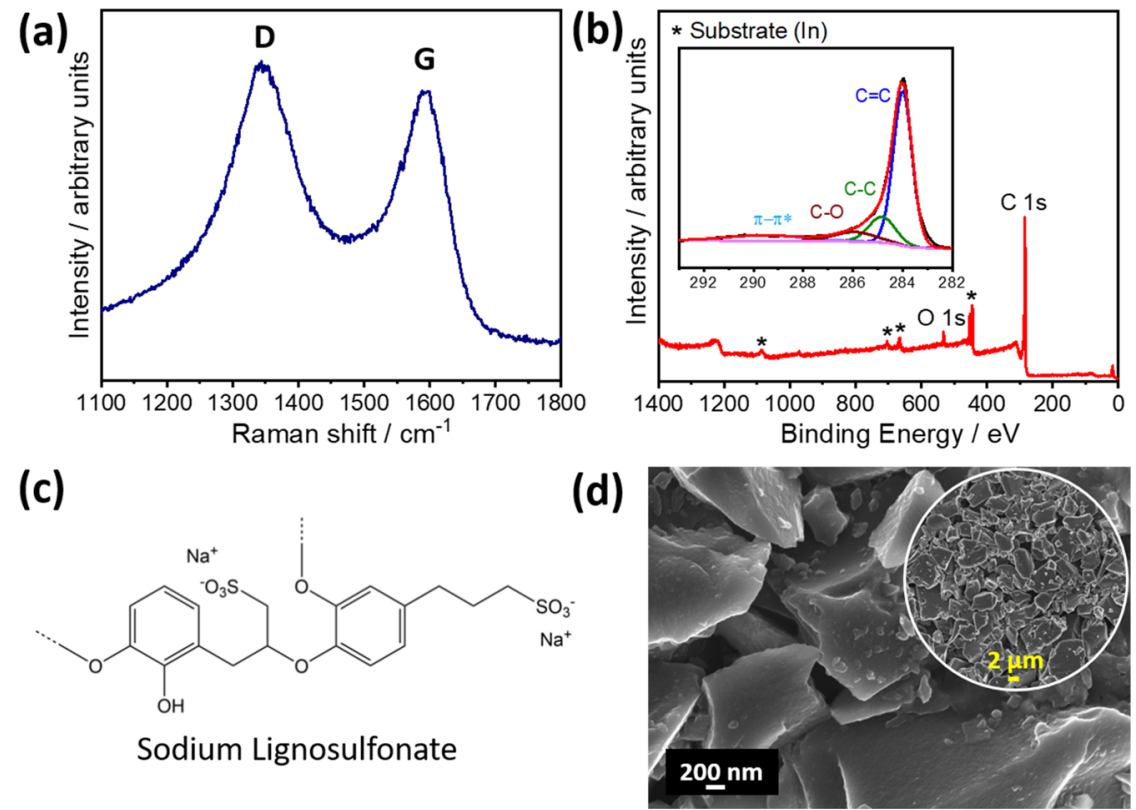

Figure 1. Physical characterization of hard carbon. (a) Raman spectrum of the as-received powder using a $532 \mathrm{~nm}$ excitation laser. (b) XPS survey spectrum (indium peaks from the substrate indicated by asterisks); inset: high-resolution C 1s spectrum. (c) Chemical structure of the LgSA (sodium lignosulfonate) binder. (d) SEM images at two magnifications of the as-prepared LgSA-based hard carbon electrode.

to the choice of a binder for a hard carbon anode is important to the successful commercialization of SIBs. ${ }^{30-37}$

Herein, we introduce sodium lignosulfonate as a watersoluble binder in hard carbon electrodes for SIBs, which is potentially both cost-effective and environmentally friendly. Its performance is evaluated using galvanostatic battery cycling against other water-soluble binders including sodium carboxymethyl cellulose ("CMC") and sodium alginate ("Alg"), along with an NMP-soluble softwood kraft lignin ("Lg") binder. In addition, the impact of the LgSA and CMC binders on the composition of the SEI layer is investigated by X-ray photoelectron spectroscopy (XPS).

\section{EXPERIMENTAL METHODS}

Electrode Preparation. Electrodes were prepared by mixing a commercial hard carbon powder (Kuranode Type 3, Kuraray) and binder in a weight ratio of 95:5. The binders used were sodium lignosulfonate (Sigma-Aldrich, average $M_{\mathrm{w}}: 52,000 \mathrm{~g} \mathrm{~mol}^{-1}$, average $M_{\mathrm{n}}: 7000 \mathrm{~g} \mathrm{~mol}^{-1}$ ), sodium alginate (Sigma-Aldrich, from brown algae, medium viscosity), sodium carboxymethyl cellulose (SigmaAldrich, average $M_{\mathrm{w}}: 700,000 \mathrm{~g} \mathrm{~mol}^{-1}$ ), and softwood kraft lignin (LignoBoost process; $M_{\mathrm{w}}: 5300 \mathrm{~g} \mathrm{~mol}^{-1}$ ) obtained from the Research Institutes of Sweden (RISE). Styrene-butadiene rubber (SBR; StyronXZ-94453, 50\%) was purchased from Styron Europe Leclanché $\mathrm{GmbH}$ and added in an equal weight ratio with the LgSA binder (hard carbon:LgSA:SBR, 95:2.5:2.5). Slurries were formed by adding $\sim 3$ to $6 \mathrm{~mL}$ per gram of solids, depending upon the binder, of deionized water (DI), or NMP ( $N$-methyl-2-pyrrolidone, SigmaAldrich, anhydrous, 99.5\%) and mixed by a vortex homogenizer (Vortex Genie2 from Scientific Industries). Using a doctor blade (200 $\mu \mathrm{m}$ spacing), the slurry was cast onto carbon-coated $\mathrm{Al}$ foil and allowed to dry under ambient conditions overnight. Discs $(13 \mathrm{~mm})$ were punched out of the coating and further dried at $120^{\circ} \mathrm{C}$ under vacuum (Büchi Glass Oven B-585) for $12 \mathrm{~h}$, resulting in electrodes with a mass-loading range between 1.9 and $3.1 \mathrm{mg} \mathrm{cm}^{-2}$. To prepare Prussian white (PW) electrodes, Prussian white powder supplied by Altris $\mathrm{AB}$ was mixed (by a vortex homogenizer) with Super P (Alfa Aesar, 99+ \%) carbon black and a CMC binder in an 85:10:5 weight ratio using $\sim 5 \mathrm{~mL}$ per gram of solids of a 9:1 (v/v) DI:ethanol mixture to obtain a homogeneous slurry. The slurry was cast onto carbon-coated aluminum foil using a doctor blade (150 $\mu \mathrm{m}$ spacing) from which $13 \mathrm{~mm}$ diameter discs were punched and dried at $140{ }^{\circ} \mathrm{C}$ under vacuum for $24 \mathrm{~h}$. The difference in doctor blade spacings relates to the desired mass balance for HC and PW electrodes for full-cells. For half-cells and three-electrode tests, $14 \mathrm{~mm}$ diameter $\mathrm{Na}$ metal disc reference electrodes were prepared from $\mathrm{Na}$ metal cubes $(99.9 \%$ trace-metal basis, Sigma-Aldrich). For full-cells, the PW mass loading was 1.9 times that of the hard carbon electrode to maintain charge balance between the anode and cathode (Supporting Information, Section S1).

Scanning Electron Microscopy. As-prepared hard carbon electrodes were mounted on $\mathrm{Al}$ stubs using adhesive carbon tabs (Agar Scientific). Scanning electron microscopy images were acquired using an SEM/EDS-Zeiss 1550 instrument operated at an acceleration voltage of $5.0 \mathrm{kV}$ using an in-lens detector.

Raman Spectroscopy. The Raman spectrum of the commercial hard carbon powder was measured using a Renishaw inVia Raman spectrometer equipped with a solid-state $532 \mathrm{~nm}$ laser that was focused with a $50 \times$ objective lens and operated at $0.5 \%$ of its $50 \mathrm{~mW}$ power.

Cell Assembly and Electrochemical Measurements. The electrochemical performance of the hard carbon electrodes was evaluated in pouch cells assembled in an Ar-filled glovebox (GS Glovebox Systemtechnik) in which $\mathrm{O}_{2}$ and $\mathrm{H}_{2} \mathrm{O}$ levels were below 1 $\mathrm{ppm}$. In half-cells, the hard carbon electrodes were the working electrodes, while a $14 \mathrm{~mm}$ diameter $\mathrm{Na}$ disc was used as the counter and reference electrode. Three-electrode full-cells consisted of a Prussian white (PW) working electrode, hard carbon counter electrode, and $\mathrm{Na}$ metal reference electrode. A schematic representation of the three-electrode cell configuration is shown in Figure S1. Glass fiber separators (Whatman, GF/A) of $240 \mu \mathrm{m}$ in thickness were dried under vacuum at $100{ }^{\circ} \mathrm{C}$ for $6 \mathrm{~h}$ to remove moisture before cell preparation. The electrolytes used in this study consisted of $1.0 \mathrm{M} \mathrm{NaPF}_{6}$ (Stella Chemifa, 98+ \%) in propylene carbonate (PC; Sigma-Aldrich, 99\%) and ethylene carbonate (EC; 99\%, Sigma-Aldrich)/diethyl carbonate (DEC; Sigma-Aldrich, 99\%) $(1: 1 \mathrm{v} / \mathrm{v})$. For electrolyte preparation, the $\mathrm{NaPF}_{6}$ salt was dried for 24 $\mathrm{h}$ under vacuum at $120{ }^{\circ} \mathrm{C}$. Approximately $200-300 \mu \mathrm{L}$ of the electrolyte was added to cells. Prior to electrochemical tests, the cells were allowed to rest at open circuit voltage (OCV) for $24 \mathrm{~h}$. Galvanostatic cycling tests were carried out on the half-cells and full- 


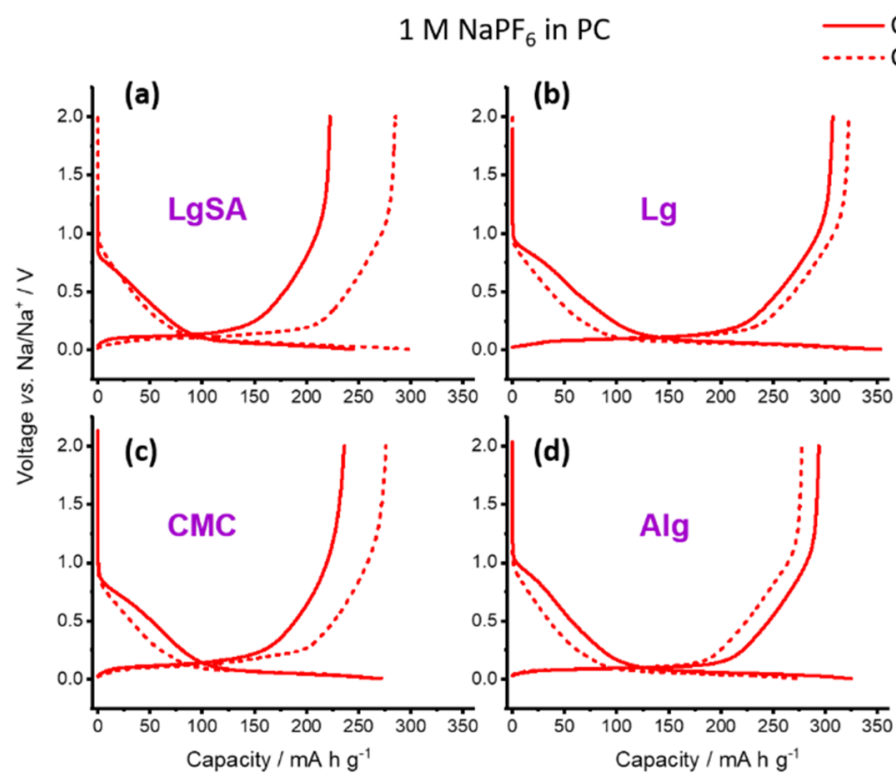

Cycle 1

Cycle 10
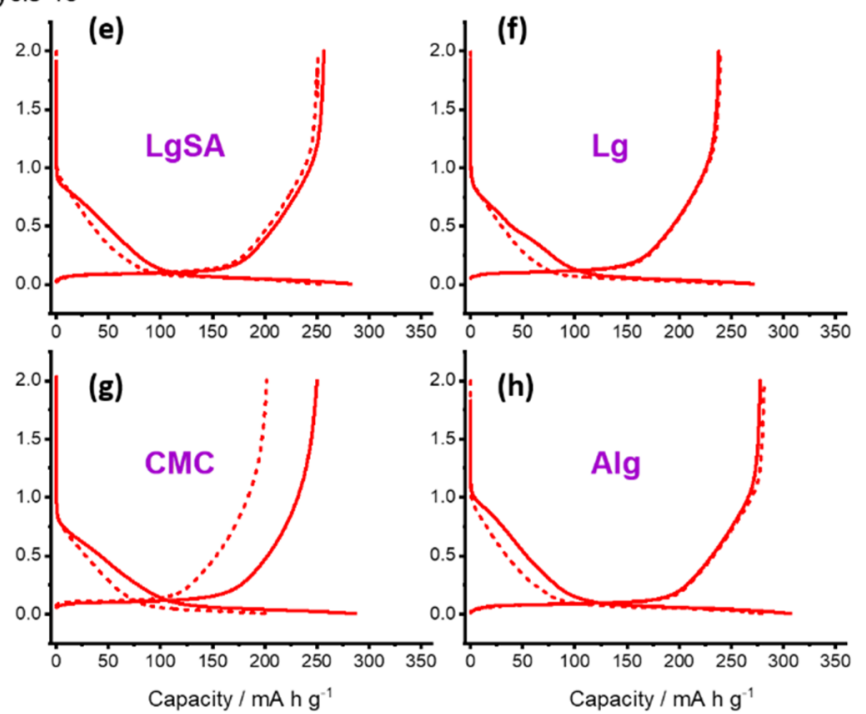

Figure 2. Voltage profiles for the 1st (solid line) and 10th (dashed line) galvanostatic cycles for hard carbon electrodes in three-electrode sodium half-cell configuration at a rate of C/5 using different binders (a) LgSA, (b) Lg, (c) CMC, and (d) Alg in $1 \mathrm{M} \mathrm{NaPF}_{6}$ in PC and (e) LgSA, (f) Lg, (g) $\mathrm{CMC}$, and (h) Alg in $1 \mathrm{M} \mathrm{NaPF}_{6}$ in the (1:1) EC:DEC electrolyte.

cells in the voltage range from 0.005 to $2 \mathrm{~V}$ vs Na/Na ${ }^{+}$and 1 to $4 \mathrm{~V}$, respectively, using a Biologic MPG2 potentiostat. Half-cell measurements were carried out at a $\mathrm{C} / 5$ rate $\left(60 \mathrm{~mA} \mathrm{~g}^{-1}\right)$ assuming a maximum capacity of $300 \mathrm{~mA} \mathrm{~h} \mathrm{~g}^{-1}$ for the commercial hard carbon. The maximum capacity of commercial hard carbon (with CMC binder) was determined using a three-electrode half-cell configuration with Celgard 2400 and glass fiber separators (Figure S2). The cell was subjected to a potential range of $0.005-2.5 \mathrm{~V}$ and currents of 10,20 , 40,60 , and again $10 \mathrm{~mA} \mathrm{~g}^{-1}$. In the interest of clarity, for the results presented relating to half-cells, the first step (sodiation of hard carbon) is denoted as a "discharge". However, as is conventional, the first step for a full-cell (desodiation of PW; sodiation of hard carbon) is denoted as a "charge".

X-ray Photoelectron Spectroscopy. XPS measurements were performed on the as-received commercial hard carbon powder, asprepared electrodes, and cycled hard carbon electrodes, which used LgSA and CMC binders. Spectra were recorded using a PHI 5500 spectrometer equipped with a monochromatic $\mathrm{Al} \mathrm{K} \alpha$ X-ray source $(1487 \mathrm{eV})$. Hard carbon powder was placed on an indium metal substrate mounted on double-sided copper tape. Pristine LgSA-based and CMC-based hard carbon electrodes were mounted on copper tape. Cells for XPS analysis contained a Celgard 2400 separator facing the hard carbon to prevent contamination of the surface by glass fibers. The cells were disassembled inside the glovebox, and hard carbon electrodes were immediately washed by dropping $1 \mathrm{~mL}$ of dimethyl carbonate (DMC) over the electrode surface. Diethyl carbonate (DEC) was used as the washing solvent for electrodes from half-cells, where the electrodes were washed in a similar way. The software package CasaXPS was used for peak fitting of the highresolution spectra after a Shirley background subtraction. Energy calibration was performed by setting the binding energy for the $\mathrm{sp}^{3}$ carbon $(\mathrm{C}-\mathrm{C})$ in the $\mathrm{C} 1 \mathrm{~s}$ spectra to $284.8 \mathrm{eV}$. Spectra were normalized individually apart from where the signal is very small or absent, indicating that a particular element is not present in a sample.

\section{RESULTS AND DISCUSSION}

Structural Characterization of Hard Carbon. As can be seen in Figure 1a, the Raman spectrum shows characteristic D and $\mathrm{G}$ bands at 1343 and $1593 \mathrm{~cm}^{-1}$, respectively, typical for the disordered structure of hard carbon. ${ }^{38}$ The XPS survey spectrum, displayed in Figure 1b, shows the presence of carbon
(C $1 \mathrm{~s}, \sim 284 \mathrm{eV})$ and oxygen $(\mathrm{O} 1 \mathrm{~s}, \sim 532 \mathrm{eV})$ as well as indium from the substrate, confirming the elemental purity of the hard carbon. The inset in Figure $1 \mathrm{~b}$ presents the highresolution $\mathrm{C} 1 \mathrm{~s}$ region, for which contributions from both $\mathrm{sp}^{2}$ hybridized $\mathrm{C}(\mathrm{C}=\mathrm{C}, \sim 284 \mathrm{eV})$ and $\mathrm{sp}^{3}$-hybridized $\mathrm{C}(\mathrm{C}-\mathrm{C}$, $284.8 \mathrm{eV}$ ) are fitted. A further peak for $\mathrm{C}-\mathrm{O}$ at $285.9 \mathrm{eV}$ is fitted and attributed to surface functionalization of the hard carbon with oxygen.

The SEM analysis, as shown in Figure 1d, of the as-prepared hard carbon electrode, which used the LgSA binder (chemical structure in Figure 1c), reveals a typical particle size of $\sim 5 \mu \mathrm{m}$, consistent with specifications from the manufacturer. In addition, no difference is observed in the morphology of the particles or electrodes regardless of the binder used for the electrode preparation (Figure S3).

Electrochemical Performance. In Figure $2 a-d$, the 1st and 10th galvanostatic charge-discharge curves are shown for three-electrode cells with hard carbon electrodes prepared with different binders and using $1 \mathrm{M} \mathrm{NaPF}_{6}$ in the PC electrolyte. The first discharge capacities (with a lower cut-off potential of $0.005 \mathrm{~V}$ ) for hard carbon using LgSA, Lg, CMC, and Alg binders are found to be $244,353,266$, and $320 \mathrm{~mA} \mathrm{~h} \mathrm{~g}^{-1}$, respectively, while first charge capacities (at $2.0 \mathrm{~V}$ ) are 222, 307,237 , and $295 \mathrm{~mA} \mathrm{~h} \mathrm{~g}^{-1}$, respectively. The 10th discharge capacities are $299,324,277$, and $280 \mathrm{~mA} \mathrm{~h} \mathrm{~g}$, and the corresponding 10th cycle charge capacities are $284,322,275$, and $277 \mathrm{~mA} \mathrm{~h} \mathrm{~g}^{-1}$, respectively. With the PC-based electrolyte, quite a difference in initial capacities and performance over the first 10 cycles is observed for the various binders. Of particular interest is the significant increase in capacities for the lignosulfonate-based electrode between the 1st and 10th cycles and, similarly, for the charge capacity of the CMC-based electrode.

The performance was further assessed using an alternative electrolyte. The charge-discharge profiles using the electrolyte $1 \mathrm{M} \mathrm{NaPF}_{6}$ in (1:1) EC:DEC are presented in Figure 2e-h. First discharge capacities (at $0.005 \mathrm{~V}$ ) using $\mathrm{LgSA}, \mathrm{Lg}, \mathrm{CMC}$, and Alg binders are found to be 282, 270, 286, and $306 \mathrm{~mA} \mathrm{~h}$ 

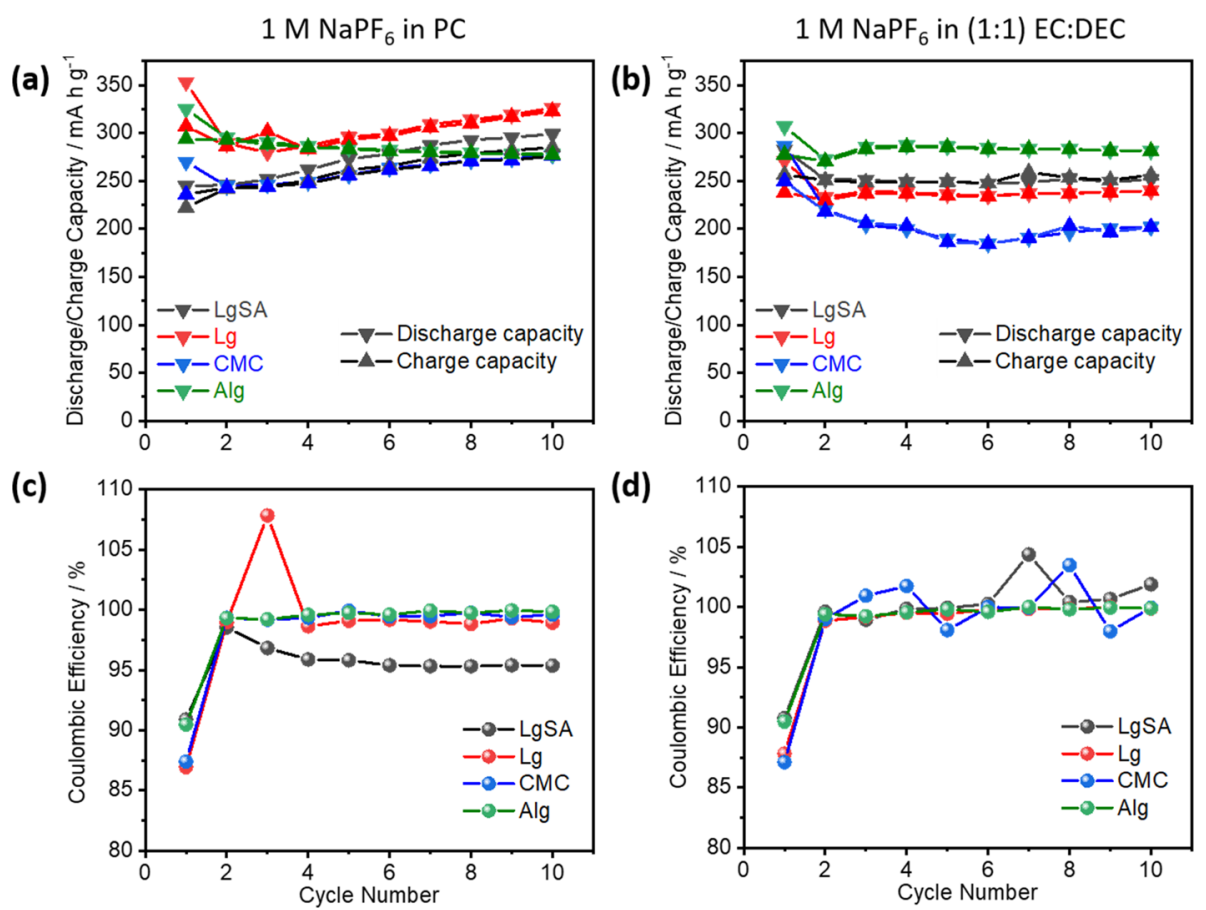

Figure 3. Charge and discharge specific capacities vs cycle number for hard carbon electrodes in three-electrode half-cell configuration using different binders at $\mathrm{C} / 5\left(60 \mathrm{~mA} \mathrm{~g}^{-1}\right)$ with (a) $1 \mathrm{M} \mathrm{NaPF}_{6}$ in PC and (b) $1 \mathrm{M} \mathrm{NaPF}_{6}$ in (1:1) EC:DEC electrolytes. Corresponding Coulombic efficiencies of the cells with (c) $1 \mathrm{M} \mathrm{NaPF}_{6}$ in PC and (d) $1 \mathrm{M} \mathrm{NaPF}_{6}$ in (1:1) EC:DEC electrolytes.

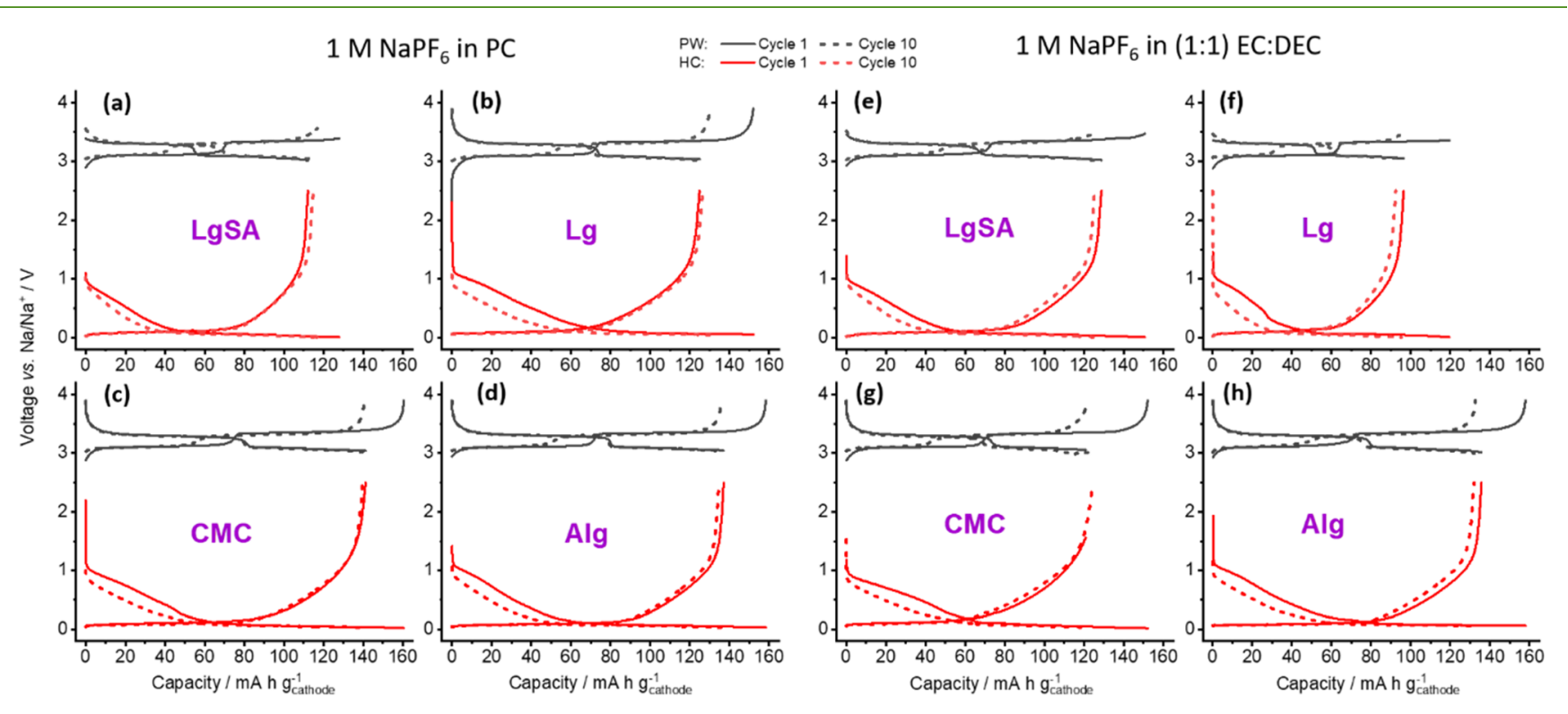

Figure 4. Voltage profiles for the 1 st (solid line) and 10th (dashed line) galvanostatic cycle $(\mathrm{C} / 5$ rate) for hard carbon electrodes in three-electrode full-cell configuration (PW as the cathode) using different binders (a) LgSA, (b) Lg, (c) CMC, and (d) Alg in $1 \mathrm{M} \mathrm{NaPF}_{6}$ in PC and (e) LgSA, (f) $\mathrm{Lg}$, (g) CMC, and (h) Alg in $1 \mathrm{M} \mathrm{NaPF}_{6}$ in the (1:1) EC:DEC electrolyte.

$\mathrm{g}^{-1}$, respectively. The first charge capacities (at $2.0 \mathrm{~V}$ ) are 257 , 238,250 , and $278 \mathrm{~mA} \mathrm{~h} \mathrm{~g}^{-1}$, respectively. The 10th discharge capacities are $253,240,206$, and $280 \mathrm{~mA} \mathrm{~h} \mathrm{~g}^{-1}$, while the corresponding charge capacities for the 10th cycle are 251, 239, 201, and $282 \mathrm{~mA} \mathrm{~h} \mathrm{~g}^{-1}$, respectively.

For all of the binders, the general shape of the voltage profiles is observed to be almost identical. However, differences in capacity are evident, depending on the binder employed and the electrolyte. For example, the CMC-based electrode exhibits an increase in charge capacity from the 1 st to 10th cycle in the PC-based electrolyte but a significant decrease when using the EC:DEC-based electrolyte.

The cycling performance is summarized in Figure $3 a, b$, while Figure $3 c$,d shows the Coulombic efficiencies. The first cycle Coulombic efficiencies for electrodes with LgSA, Lg, CMC, and Alg binders and $1 \mathrm{M} \mathrm{NaPF}_{6}$ in the PC electrolyte are 91, 87,87 , and $90 \%$, respectively, which increase to $\sim 95 \%$ for $\mathrm{LgSA}$ and close to $99 \%$ for $\mathrm{Lg}, \mathrm{CMC}$, and Alg. For $1 \mathrm{M} \mathrm{NaPF}_{6}$ in the (1:1) EC:DEC electrolyte, Coulombic efficiencies of 91, 88,87 , and $90 \%$ are determined for the first cycle. With very similar first cycle efficiencies as for the PC electrolyte, the 
$1 \mathrm{M} \mathrm{NaPF}_{6}$ in $\mathrm{PC}$

(a)

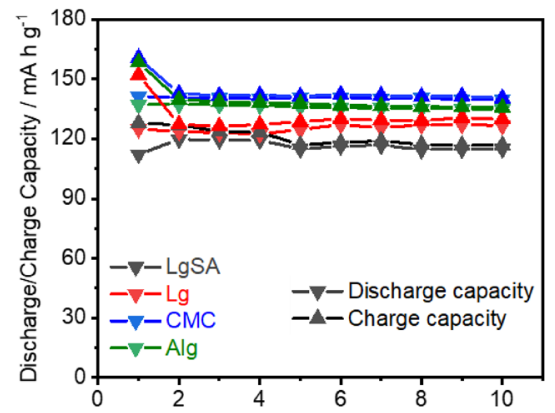

(c)

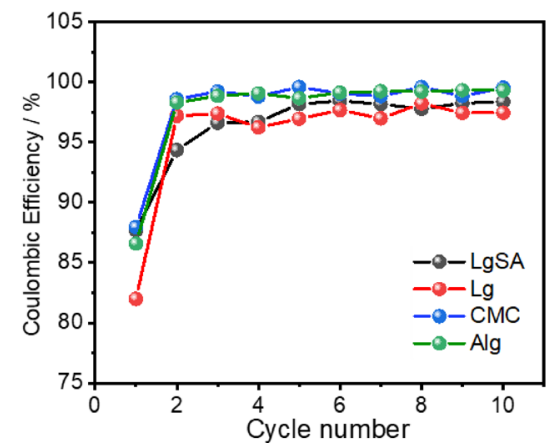

$1 \mathrm{M} \mathrm{NaPF}_{6}$ in (1:1) EC:DEC

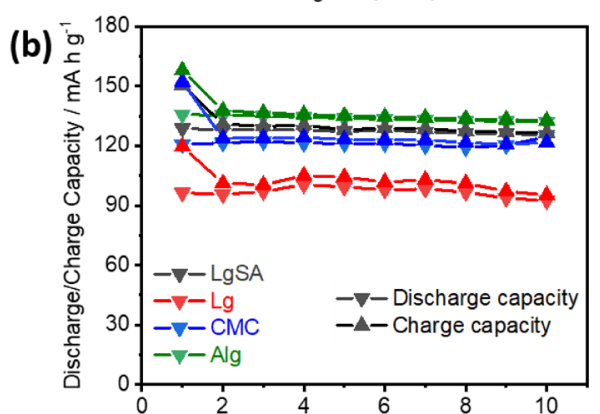

(d)

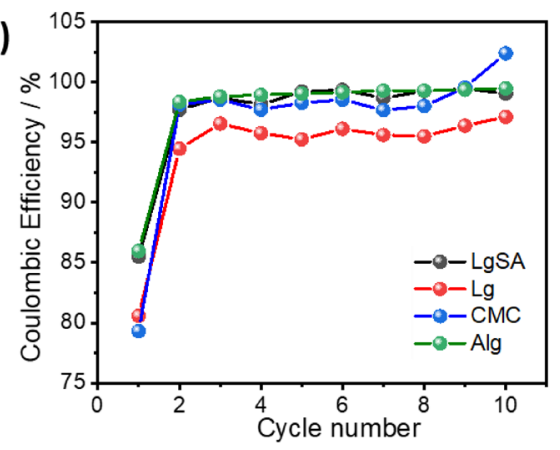

Figure 5. Cycling performance of hard carbon in three-electrode full-cell configuration using different binders with PW as a positive electrode at C/ 5 in (a) $1 \mathrm{M} \mathrm{NaPF}_{6} / \mathrm{PC}$ and (b) $1 \mathrm{M} \mathrm{NaPF}_{6} /(1: 1)$ EC:DEC electrolytes. Corresponding Coulombic efficiency of all binders in the full-cell in (c) 1 $\mathrm{M} \mathrm{NaPF}_{6} / \mathrm{PC}$ and (d) $1 \mathrm{M} \mathrm{NaPF}_{6} /(1: 1)$ EC:DEC electrolytes.

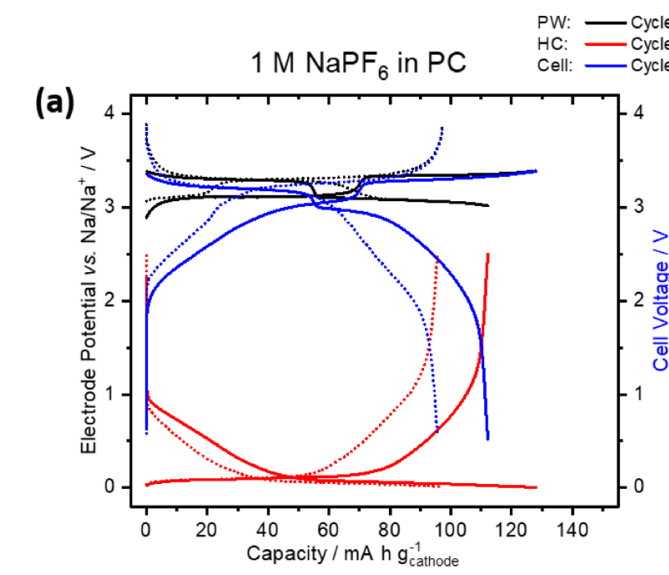

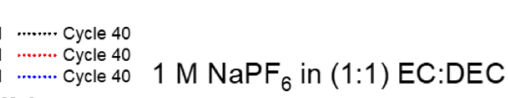
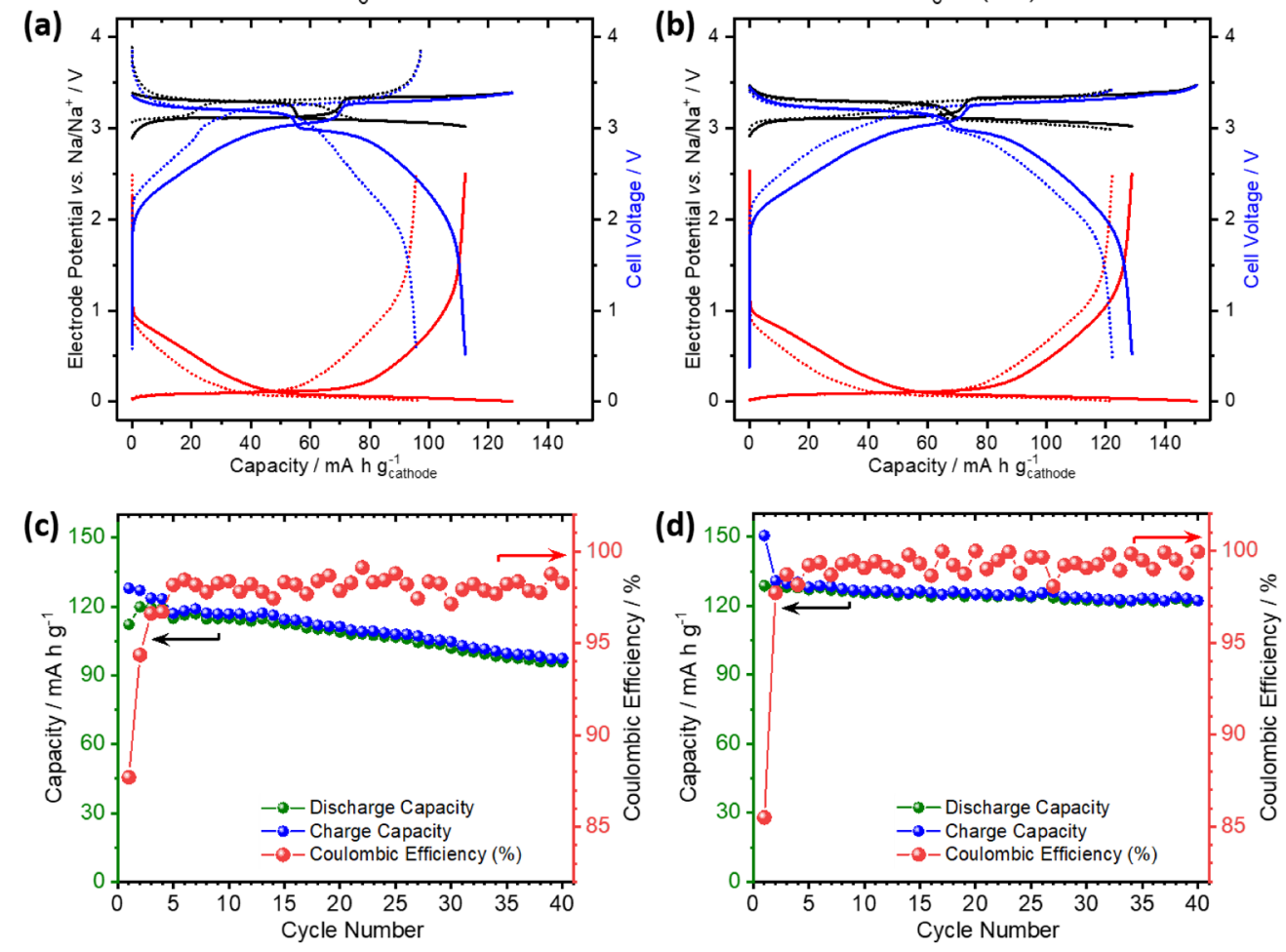

Figure 6. Galvanostatic voltage profiles of hard carbon using the LgSA binder in three-electrode full-cell configuration with PW as the cathode for the 1st (solid line) and 40th (dashed line) cycles in (a) $1 \mathrm{M} \mathrm{NaPF}_{6}$ in PC and (b) $1 \mathrm{M} \mathrm{NaPF}_{6}$ in the (1:1) EC:DEC electrolyte at a rate of C/5. The corresponding cycling performance and Coulombic efficiency $(c, d)$.

values then generally become close to $99 \%$ in subsequent cycles. In a few instances, for both electrolytes, the Coulombic efficiency is greater than $100 \%$. We attribute this to the oxidation (on charge) of surface species on hard carbon, which may have formed through electrolyte decomposition or crosstalk from the use of the $\mathrm{Na}$ metal counter electrode in the half- 
cells. This can result in greater capacities on charge than discharge for particular cycles and hence inconsistencies in the Coulombic efficiency.

The electrodes with the lignosulfonate binder are seen to offer capacities comparable to those with other binders. While LgSA suffers from poorer Coulombic efficiences with the PCbased electrolyte, stable cycling and high efficiencies are obtained for the EC:DEC-based electrolyte when compared with CMC.

From this initial performance analysis using half-cells, it is evident that the binder and electrolyte composition can have a drastic effect on the initial capacities and stability of the cell. This phenomenon has been observed in previous studies, ${ }^{27,39}$ and can not only, for example, be correlated with the molecular weight of the binder ${ }^{40}$ but is likely also be affected by many other factors. To eliminate the effects of various detrimental traits of using half-cells, ${ }^{41}$ the hard carbon electrodes with different binders were tested additionally in full-cell configuration against a Prussian white cathode. Figure 4 presents the voltage profiles of electrodes with $\mathrm{LgSA}, \mathrm{Lg}, \mathrm{CMC}$, and $\mathrm{Alg}$ binders. As above, the two electrolytes $1 \mathrm{M} \mathrm{NaPF}_{6}$ in $\mathrm{PC}$ and 1 $\mathrm{M} \mathrm{NaPF} 6$ in (1:1) EC:DEC are compared. First cycle discharge capacities for the PC-based electrolyte using LgSA, Lg, CMC, and Alg binders are 112, 129, 142, and $137 \mathrm{~mA} \mathrm{~h}$ $\mathrm{g}^{-1}$, respectively. Those for the 10 th cycle are $115,126,140$, and $135 \mathrm{~mA} \mathrm{~h} \mathrm{~g}{ }^{-1}$, respectively. For the EC:DEC-based electrolyte, the first cycle discharge capacities are 129, 97, 121, and $136 \mathrm{~mA} \mathrm{~h} \mathrm{~g}^{-1}$, while those at the 10th cycle are 125,92 , 125 , and $131 \mathrm{~mA} \mathrm{~h} \mathrm{~g}^{-1}$, respectively.

The stability of the cycling over 10 cycles appears more stable for all binders and both electrolytes than that observed in half-cell configuration, likely as a result of replacing $\mathrm{Na}$ metal as the counter electrode. The electrochemical performance is summarized in Figure $5 a, b$, along with the corresponding Coulombic efficiencies shown in Figure $5 c$,d. The first cycle Coulombic efficiencies for the PC-based electrolyte are found to be $88,82,88$, and $87 \%$ for LgSA, $\mathrm{Lg}, \mathrm{CMC}$, and Alg binders, respectively. Up to the 10th cycle, the Coulombic efficiencies generally stabilize at $~ 97-99 \%$, depending on the binder in the hard carbon electrode. For the EC:DEC-based electrolyte, first cycle Coulombic efficiencies are determined to be $85,81,79$, and $86 \%$, respectively, which stabilize to $\sim 95-99 \%$ in subsequent cycles.

While the lignosulfonate-based electrode exhibits stable cycling in both PC and EC:DEC-based electrolytes, it generally performs better with EC:DEC. As well as excellent Coulombic efficiencies from the lignosulfonate, only the alginate electrode shows slightly improved capacities over the lignosulfonate.

The suitability of the LgSA binder for longer-term cycling was further investigated in full-cells of hard carbon and Prussian white. Figure 6 shows the galvanostatic voltage profiles, capacity evolution, and Coulombic efficiency plots for cells using the same electrolytes as employed previously. While the initial capacities for both electrolytes are approximately similar, quite a large difference is observed in the capacities after 40 cycles, with a particularly fast fading for the cell with PC. For PC, the charge capacity decreases from 127 to $97 \mathrm{~mA}$ $\mathrm{h} \mathrm{g}^{-1}$ (cycle 2-40; 23.6\% decrease), while for EC:DEC, the corresponding decrease is from 131 to $122 \mathrm{~mA} \mathrm{~h} \mathrm{~g}^{-1}$ (cycle 240; $6.9 \%$ decrease). This suggests that a longer cycle life would be possible for hard carbon anodes with the LgSA binder when using the EC:DEC-based electrolyte. The first cycle Coulombic efficiency for the cell with the PC-based electrolyte is $88 \%$, increasing to $93 \%$ for the second cycle and then stabilizing at $\sim 98 \%$ after 40 cycles. For the EC:DEC-based electrolyte, the Coulombic efficiencies for the first and second cycles are $\sim 85$ and $\sim 98 \%$, respectively, and then averaging more than $99 \%$ by 40 cycles.

Hard Carbon Electrodes with a Mixed LgSA-SBR Binder. With the aim to further improve the performance, a dual binder, LgSA and SBR in an equal weight ratio, was investigated. SBR is also a water-based binder known to possess a high flexibility and strong binding force. ${ }^{39,42}$ Figure $7 \mathrm{a}, \mathrm{b}$ presents voltage profiles from galvanostatic testing for
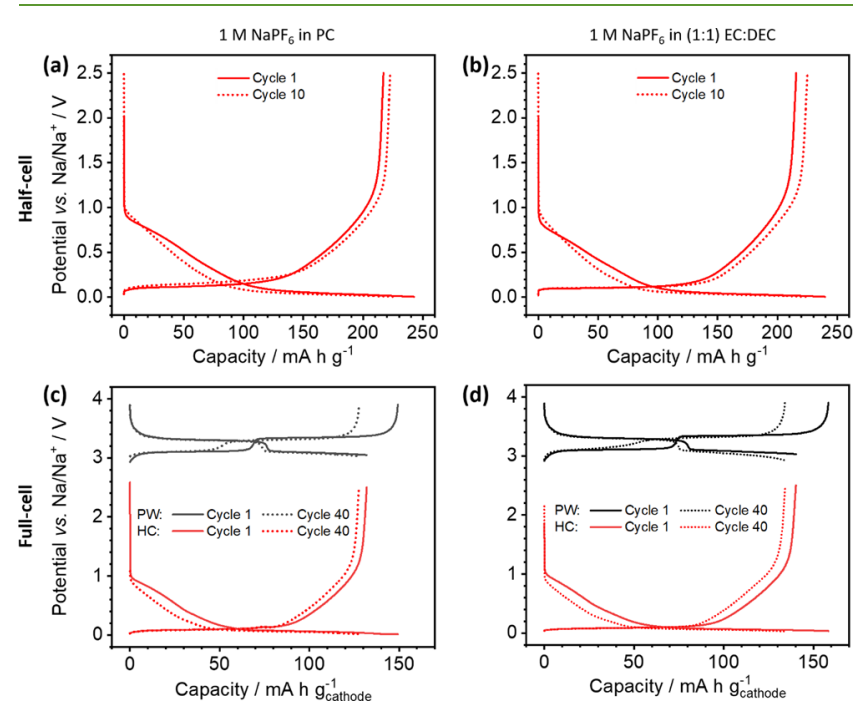

Figure 7. Galvanostatic voltage profiles ( $\mathrm{C} / 5$ rate) for the 1st (solid line) and 10th (dashed line) cycles of three-electrode half-cells using hard carbon electrodes with a LgSA-SBR binder mixture and electrolytes (a) $1 \mathrm{M} \mathrm{NaPF}_{6}$ in PC and (b) $1 \mathrm{M} \mathrm{NaPF}_{6} /(1: 1) \mathrm{EC}$ in DEC. Galvanostatic voltage profiles $(\mathrm{C} / 5$ rate) for the 1 st (solid line) and 40th (dashed line) cycle of three-electrode full-cells using hard carbon electrodes with a LgSA-SBR binder mixture and electrolytes (c) $1 \mathrm{M} \mathrm{NaPF}_{6}$ in $\mathrm{PC}$ and (d) $1 \mathrm{M} \mathrm{NaPF}_{6}$ in (1:1) EC:DEC.

half-cells using hard carbon electrodes with the mixed binder. For the PC-based electrolyte, an initial discharge capacity of $242 \mathrm{~mA} \mathrm{~h} \mathrm{~g}^{-1}$ is recorded, which fades to $222 \mathrm{~mA} \mathrm{~h} \mathrm{~g}^{-1}$ for the 10th cycle. Similarly, for the EC:DEC-based electrolyte, the 1st and 10th discharge capacities are 239 and $223 \mathrm{~mA} \mathrm{~h} \mathrm{~g}$, respectively. In full-cell configuration (Figure $7 \mathrm{c}, \mathrm{d}$ ), initial charge capacities of $149 \mathrm{~mA} \mathrm{~h} \mathrm{~g}{ }^{-1}$ using the PC-based electrolyte and $158 \mathrm{~mA} \mathrm{~h} \mathrm{~g}^{-1}$ for the EC:DEC-based electrolyte are obtained.

The corresponding cycling performances as well as Coulombic efficiencies for both the half- and full-cells are plotted in Figure 8. The Coulombic efficiencies in all cases are found to be $\sim 88-89 \%$ for the first cycle, which soon reached $\sim 99 \%$ in subsequent cycles. The full-cells demonstrate excellent capacity retention without significant fading. A decrease in charge capacity from 133 to $128 \mathrm{~mA} \mathrm{~h} \mathrm{~g}^{-1}$ (cycle $2-40 ; 3.76 \%$ decrease) after 40 cycles is determined using PC and from 141 to $134 \mathrm{~mA} \mathrm{~h} \mathrm{~g}^{-1}$ (cycle 2-40; 4.96\% decrease) using EC:DEC.

While the electrodes with only the lignosulfonate binder cycle with good stability in the EC:DEC-based electrolyte, the addition of SBR provides excellent performance for both electrolytes. 

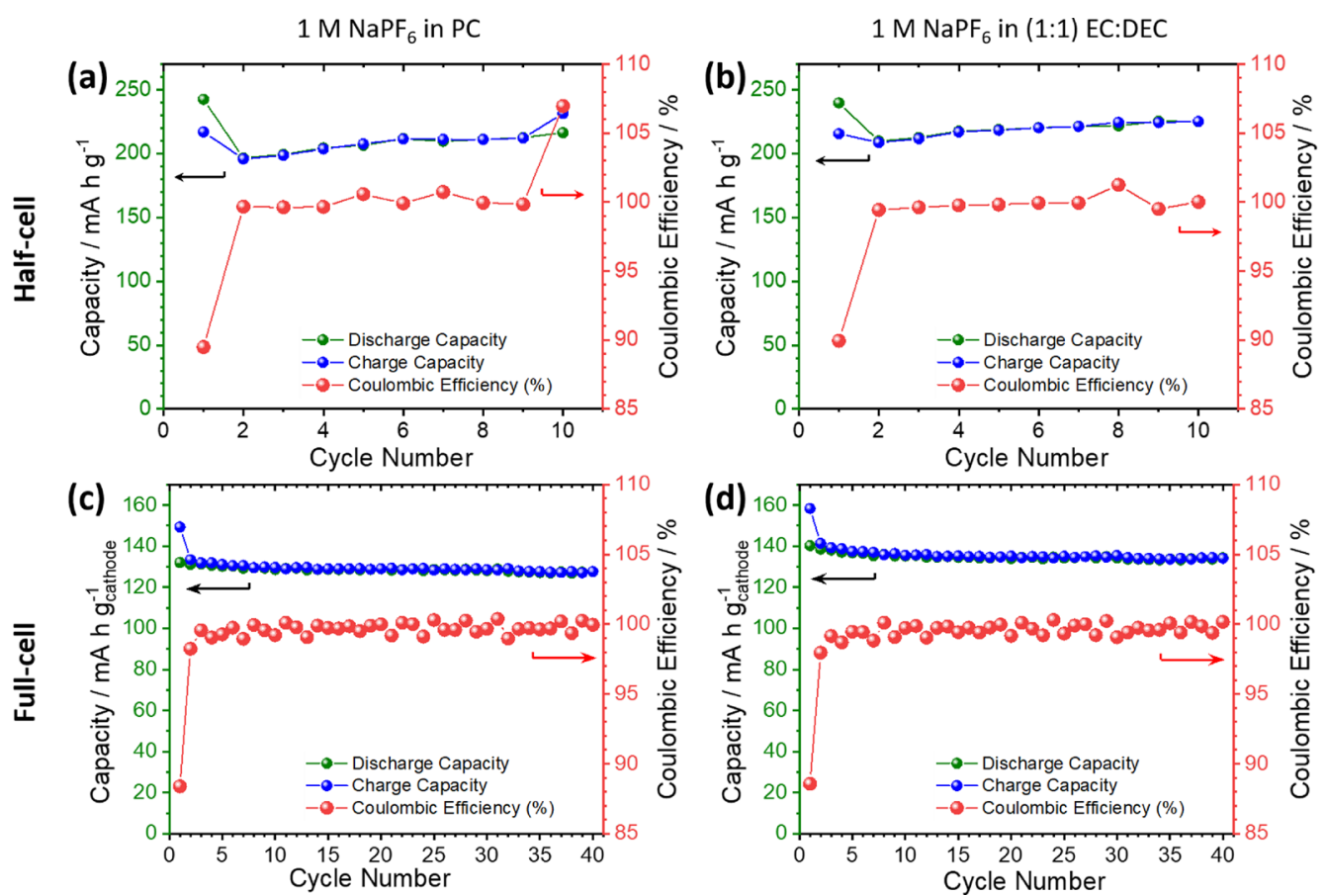

Figure 8. Cycling performance and Coulombic efficiencies of three-electrode half-cells using hard carbon with a LgSA-SBR binder mixture and electrolytes (a) $1 \mathrm{M} \mathrm{NaPF}_{6}$ in PC and (b) $1 \mathrm{M} \mathrm{NaPF}_{6}$ in (1:1) EC:DEC. Cycling performance and Coulombic efficiencies of three-electrode fullcells using hard carbon with a LgSA-SBR binder mixture and electrolytes (c) $1 \mathrm{M} \mathrm{NaPF}_{6}$ in PC and (d) $1 \mathrm{M} \mathrm{NaPF}_{6}$ in (1:1) EC:DEC.

Interface Analysis of Hard Carbon Electrodes. The significant differences in performance resulting from the use of various binders may hint toward dissimilarity of electrode interfacial properties. It is likely that different interactions between the binders and electrode material could lead to variations in the electrolyte decomposition mechanism occurring at the electrode particle surfaces. Thus, differences in electrode interfacial properties, including SEI composition and thickness, are likely to occur with the different binders used. $^{39,43}$ XPS analysis was performed on hard carbon electrodes with LgSA and CMC binders, from cells cycled over the initial two cycles, to investigate interfacial chemistry and SEI formation. Electrochemical data for the cells are presented in Figures S4 and S7. The survey spectra for the pristine hard carbon electrodes with each binder and those from disassembled cells after the first and second charge and first and second discharge state are shown in Figures S5 and S8. Such spectra indicate the presence of carbon, oxygen, and sodium as well as sulfur for LgSA-based electrodes and fluorine for cycled electrodes.

High-resolution $\mathrm{C}$ 1s and $\mathrm{O}$ 1s spectra for pristine as well as cycled LgSA- and CMC-based hard carbon electrodes are presented in Figure 9. Binding energies for the deconvoluted peaks are tabulated in Table S1. The $\mathrm{C} 1 \mathrm{~s}$ spectra show peaks for typical species including $\mathrm{sp}^{2} \mathrm{C}=\mathrm{C}(\sim 283.8 \mathrm{eV}), \mathrm{sp}^{3} \mathrm{C}-\mathrm{C}$ $(\sim 284.8 \mathrm{eV}), \mathrm{C}-\mathrm{O}(\sim 286 \mathrm{eV}), \mathrm{C}=\mathrm{O}(\sim 288.2 \mathrm{eV}), \mathrm{O}-\mathrm{C}=$ $\mathrm{O} / \mathrm{CO}_{3}{ }^{2-}(\sim 290 \mathrm{eV})$, and a binder impurity $\mathrm{C}-\mathrm{Cl}(\sim 292$ $\mathrm{eV}){ }^{44}$ The differences observed in the spectra for pristine electrodes reflect the use of different binders. For CMC, a greater relative intensity for peaks corresponding to not only, in particular, $\mathrm{C}-\mathrm{O}$ but also $\mathrm{C}=\mathrm{O}$ is observed, which is evident also in the $\mathrm{O} 1 \mathrm{~s}$ spectra. For LgSA, the $\mathrm{sp}^{3} \mathrm{C}-\mathrm{C}$ peak exhibits a high relative intensity, as would be expected. The $\mathrm{sp}^{2} \mathrm{C}=\mathrm{C}$ peak is attributed not only to the hard carbon in both pristine electrodes but also to the aromatic ring for LgSA.
For both binders after the first charge, the relative intensity of the $\mathrm{C}-\mathrm{C}$ peak is observed to increase, while the $\mathrm{C}=\mathrm{C}$ peak for hard carbon has disappeared and other peaks have very small intensities. This is thought to be due to electrolyte decomposition at the surface of the electrode, creating a thick SEI (>10 nm, based on the XPS probing depth as determined for polyethylene $\left.{ }^{45,46}\right)$, with a major component of the SEI being organic species with $\mathrm{C}-\mathrm{C}$ environments. ${ }^{47}$ For the $\mathrm{O} 1 \mathrm{~s}$ spectra, the highest intensity peaks are for $\mathrm{C}-\mathrm{O}$, likely also from organic SEI species, and carbonates (i.e., $\mathrm{Na}_{2} \mathrm{CO}_{3}$ ). The presence of a peak with a low binding energy $(\sim 530 \mathrm{eV})$ is attributed to $\mathrm{Na}_{2} \mathrm{O}$, which is further confirmed by the appearance of the Na KLL Auger peak at $\sim 535 \mathrm{eV}$.

After the first discharge (one full cycle), some differences for the two binder systems can be observed. For LgSA, the $\mathrm{C}=\mathrm{C}$ peak is observed once again but slightly shifted to a lower binding energy $(\sim 283 \mathrm{eV})$ than that of the pristine electrode. Such a shift could be attributed to the formation of $\mathrm{Na}_{x} \mathrm{C}$ during insertion of sodium into the hard carbon structure, which could remain even after desodiation. ${ }^{48}$ The reduced relative intensity of the $\mathrm{C}-\mathrm{C}$ peak and increased intensity for the peaks previously attributed to the binder suggest that the organic species on the surface of the SEI have been removed during discharge. A greater intensity for $\mathrm{O}-\mathrm{C}=\mathrm{O} / \mathrm{CO}_{3}{ }^{2-}$ is additionally observed, supporting the theory of an organic outer layer being removed to reveal an inorganic-rich SEI layer beneath. The $\mathrm{O}$ 1s spectrum shows a decreased relative intensity for $\mathrm{Na}_{2} \mathrm{O}$, returning to a similar shape as for the pristine sample. For the CMC-based electrode, the $\mathrm{C}=\mathrm{C}$ peak for hard carbon does not reappear, suggesting that a relatively thick SEI still remains on the surface. This may be confirmed through the presence of high intensity peaks for $\mathrm{O}-\mathrm{C}=\mathrm{O} /$ $\mathrm{CO}_{3}{ }^{2-}$ and $\mathrm{C}-\mathrm{O}$, which is also corroborated through the $\mathrm{O} 1 \mathrm{~s}$ spectrum. 
C 1s
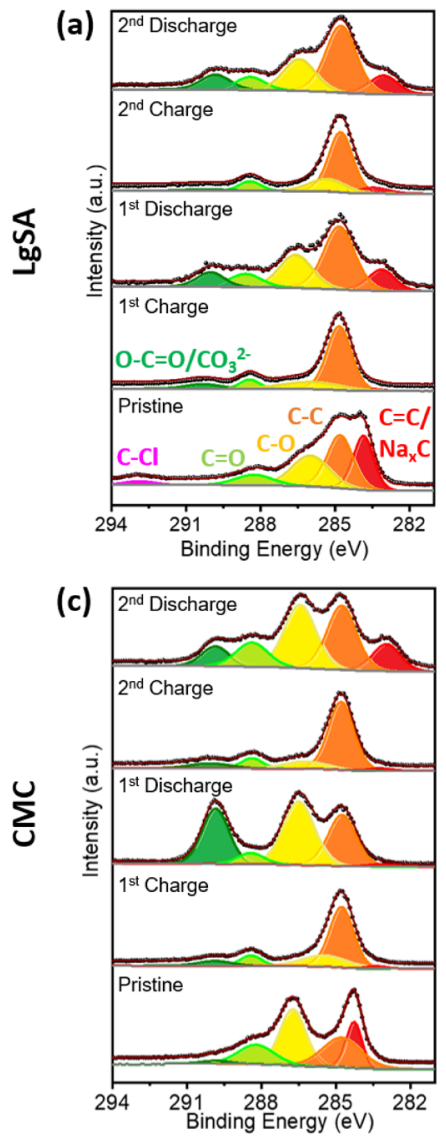

$01 \mathrm{~s}$
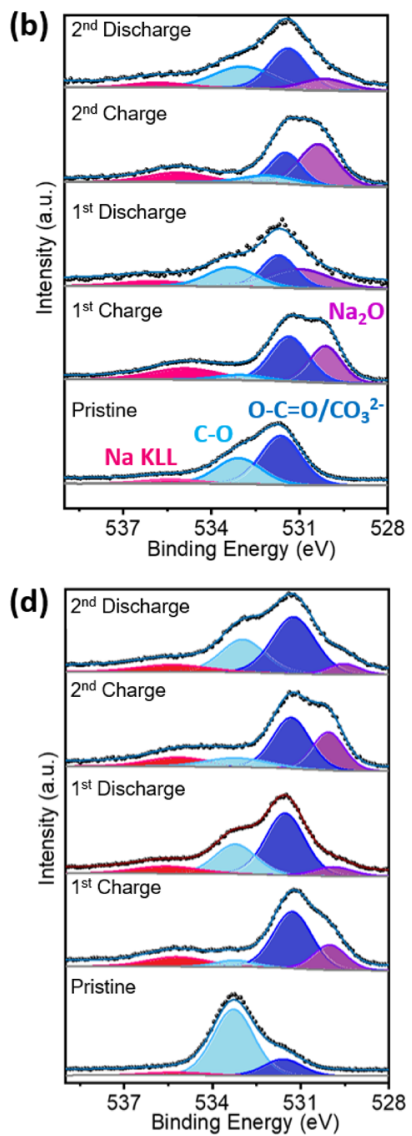

Figure 9. XPS spectra (normalized) of pristine and cycled hard carbon electrodes, from full-cells, with binders LgSA (a) C 1s and (b) $\mathrm{O} 1 \mathrm{~s}$ and $\mathrm{CMC}$ (c) $\mathrm{C} 1 \mathrm{~s}$ and (d) O 1s. Peak assignments: C 1s: sp ${ }^{2}$ $\mathrm{C}=\mathrm{C} / \mathrm{Na}_{x} \mathrm{C}$ (red), $\mathrm{sp}^{3} \mathrm{C}-\mathrm{C}$ (orange), $\mathrm{C}-\mathrm{O}$ (yellow), $\mathrm{C}=\mathrm{O}$ (light green), $\mathrm{O}-\mathrm{C}=\mathrm{O} / \mathrm{CO}_{3}{ }^{2-}$ (dark green), and $\mathrm{C}-\mathrm{Cl}$ (pink); $\mathrm{O}$ 1s: $\mathrm{Na}_{2} \mathrm{O}$ (purple), $\mathrm{C}=\mathrm{O} / \mathrm{CO}_{3}{ }^{2-}$ (dark blue), $\mathrm{C}-\mathrm{O}$ (light blue), and $\mathrm{Na}$ KLL Auger (magenta).

The second cycle charge for both LgSA- and CMC-based electrodes results in $\mathrm{C} 1 \mathrm{~s}$ and $\mathrm{O} 1 \mathrm{~s}$ spectra closely resembling those for the first charge. This suggests that the SEI has been regenerated, particularly through the formation of an organicrich surface layer (leading to an intense $\mathrm{C}-\mathrm{C}$ peak).

Likewise, for the LgSA-based electrode after two full cycles, both the $\mathrm{C} 1 \mathrm{~s}$ and $\mathrm{O} 1 \mathrm{~s}$ spectra are similar to those at the end of the first cycle. However, for the CMC-based electrode, the peak associated with the hard carbon reappears, suggesting a thinning of the SEI to reveal the electrode material beneath.

Figures $\mathrm{S} 6$ and $\mathrm{S} 9$ present $\mathrm{Na}$ 1s and $\mathrm{F}$ 1s spectra for the LgSA- and CMC-based electrodes, respectively, as well as the $S$ $2 \mathrm{p}$ spectra for $\mathrm{LgSA}$. As would be expected due to the $\mathrm{NaPF}_{6}$ salt present in the electrolyte, a fluorine signal is recorded for the cycled electrode spectra but not the pristine electrodes. It was of particular surprise that the survey spectra for hard carbon electrodes in the charged state always exhibit relatively low intensity peaks for fluorine. One might expect fluorine to be one of the most intense peaks for this state, with the SEI expected to be at its thickest and usually containing a large quantity of $\mathrm{PF}_{6}{ }^{-}$or its decomposition products $\left(\mathrm{PF}_{x}{ }^{-}, x \leq 5\right.$, or fluorine-containing organic species). A similar phenomenon and generally comparable spectra were recorded for hard carbon electrodes cycled in half-cell configuration using both

binders (Figures S10-S17 and Tables S3 and S4). However, this is consistent with a picture of the SEI for the graphitic anode in lithium-ion batteries, where a dense inorganic-rich layer $\left(\mathrm{LiF}\right.$ and $\mathrm{Li}_{2} \mathrm{CO}_{3}$ ) close to the electrode surface is coated by an organic-rich (polymeric) layer. ${ }^{49}$ As was discussed already for the $\mathrm{C} 1 \mathrm{~s}$ and $\mathrm{O} 1 \mathrm{~s}$ spectra, the diminished $\mathrm{F} 1 \mathrm{~s}$ signal during charge steps could be due to the underlying flourinated species being covered by an organic-rich layer. The SEI being dynamic in nature means that the organic species may be dissolved or stripped on discharge, leaving an inorganic-rich layer exposed, resulting in an increase in the relative peak intensity for $\mathrm{F} 1 \mathrm{~s} .{ }^{48-50}$

The pristine LgSA-based hard carbon electrode shows the presence of sodium and sulfur, both of which are present in the binder. On charge and discharge, the peak for sodium appears to shift to lower and higher binding energies, respectively, indicating different environments in each case for the sodium (e.g., binder $\mathrm{Na}$ vs $\mathrm{Na}_{2} \mathrm{O}$ vs $\mathrm{Na}_{x} \mathrm{C}$ ). A similar phenomenon is observed for the CMC-based electrodes. The clear signal for sulfur in LgSA appears for the pristine electrode but is absent on the charge steps, indicative of a thick SEI blocking the signal.

Overall, these results demonstrate the dynamic nature of the SEI on hard carbon during charge-discharge cycles. Furthermore, we observe differences in surface chemistry for electrodes with different binder systems, LgSA and CMC. This is particularly evident after the discharge step for each cycle, where the SEI has been partially stripped. Different relative intensities for the $\mathrm{C}=\mathrm{C}$ peak (hard carbon) indicate varying surface layer thicknesses, dependent on the binder used.

\section{CONCLUSIONS}

In summary, we have introduced and investigated LgSA as a promising, potentially cost-effective, and sustainable binder for hard carbon anodes in sodium-ion batteries. This comparative study with $\mathrm{Lg}, \mathrm{CMC}$, and $\mathrm{Alg}$ binders, all of which are watersoluble apart from $\mathrm{Lg}$, demonstrates $\mathrm{LgSA}$ as a viable alternative to existing binders. In half-cells, the performance was found to be highly dependent on the binder or electrolyte used. However, most binders exhibited little capacity fading and high Coulombic efficiencies when employing the EC:DEC-based electrolyte. For full-cells with a Prussian white cathode, this electrolyte allowed for excellent capacity retention up to 40 cycles. Further improvement was achieved by mixing LgSA and SBR. For both electrolytes, a capacity retention greater than $95 \%$ was obtained, while the absolute capacities were higher for the EC:DEC-based electrolyte (158 $\mathrm{mA} \mathrm{h} \mathrm{g}{ }^{-1}$ first cycle charge) than PC $\left(149 \mathrm{~mA} \mathrm{~h} \mathrm{~g}^{-1}\right)$.

XPS analysis of hard carbon electrodes with both LgSA and CMC binders revealed information about the electrodeelectrolyte interface and SEI formation. The SEI was found to consist of similar species (typically $\mathrm{C}-\mathrm{C}, \mathrm{C}-\mathrm{O}, \mathrm{C}=\mathrm{O}, \mathrm{Na}_{2} \mathrm{O}$, carbonates, and $\mathrm{PF}_{6}^{-}$decomposition products) for both electrode types. However, it was observed that the SEI was dynamic in thickness between charge and discharge steps, likely being stripped/dissolved and reformed in each cycle. Furthermore, it was revealed that the part of the SEI being stripped or that dissolved was likely to be the organic outer layer, with the F-rich inorganic layer close to the electrode surface being exposed on discharge steps. Differences were observed for the SEI between the two binder systems; for example, the SEI on the LgSA-based electrode after one full cycle was comparably thinner and had a smaller fraction of 
carbonate species. The binder was therefore demonstrated to have a considerable influence on the SEI composition and thickness, which might be important for the stability of the electrode during cycling. LgSA has been shown to offer comparable or better cycling stability and electrochemical performance, when assessed against commonly used binders, which may be as a result of the interfacial reactions occurring with the electrolyte during cycling. Based on the promising galvanostatic cycling behavior of LgSA as a novel binder, there are many opportunities for future studies. These include in situ/operando material analysis, optimization of binder-hard carbon ratio for improved performance, and mechanical and adhesive properties of the binders.

\section{ASSOCIATED CONTENT}

\section{SI Supporting Information}

The Supporting Information is available free of charge at https://pubs.acs.org/doi/10.1021/acssuschemeng.1c05263.

Charge balance calculation for full-cell fabrication, schematic of full-cell configuration, further cycling data for hard carbon electrodes, SEM images, XPS survey spectra and further high energy resolution region spectra for electrodes from half- and full-cells, and fitting parameters for XPS spectra (PDF)

\section{AUTHOR INFORMATION}

\section{Corresponding Author}

Andrew J. Naylor - Department of Chemistry - Ångström Laboratory, Uppsala University, 75121 Uppsala, Sweden; 다이.org/0000-0001-5641-7778; Email: andy.naylor@ kemi.uu.se

\section{Authors}

Ritambhara Gond - Department of Chemistry - Angström Laboratory, Uppsala University, 75121 Uppsala, Sweden

Habtom Desta Asfaw - Department of Chemistry - Ångström Laboratory, Uppsala University, 75121 Uppsala, Sweden; () orcid.org/0000-0001-5861-4281

Omid Hosseinaei - RISE Research Institutes of Sweden, 114 28 Stockholm, Sweden

Kristina Edström - Department of Chemistry - Angström Laboratory, Uppsala University, 75121 Uppsala, Sweden; (D) orcid.org/0000-0003-4440-2952

Reza Younesi - Department of Chemistry - Ångström Laboratory, Uppsala University, 75121 Uppsala, Sweden; (1) orcid.org/0000-0003-2538-8104

Complete contact information is available at: https://pubs.acs.org/10.1021/acssuschemeng.1c05263

\section{Notes}

The authors declare the following competing financial interest(s): The Prussian white powder used as positive electrode material for full cells in this study is a commercial product provided by ALTRIS AB, a company co-founded by R.Y. The other authors in this paper declare to have no competing interests.

\section{ACKNOWLEDGMENTS}

The project was financially supported by ÅForsk via grant 19638 and the Swedish Energy Agency (project no. 48198-1). The authors would like to acknowledge STandUP for Energy.

\section{REFERENCES}

(1) Bresser, D.; Buchholz, D.; Moretti, A.; Varzi, A.; Passerini, S. Alternative Binders for Sustainable Electrochemical Energy Storagethe Transition to Aqueous Electrode Processing and Bio-Derived Polymers. Energy Environ. Sci. 2018, 11, 3096-3127.

(2) Lu, H.; Cornell, A.; Alvarado, F.; Behm, M.; Leijonmarck, S.; Li, J.; Tomani, P.; Lindbergh, G. Lignin as a Binder Material for EcoFriendly Li-Ion Batteries. Materials (Basel). 2016, 9, 127.

(3) Dahbi, M.; Nakano, T.; Yabuuchi, N.; Ishikawa, T.; Kubota, K.; Fukunishi, M.; Shibahara, S.; Son, J. Y.; Cui, Y. T.; Oji, H.; Komaba, S. Sodium Carboxymethyl Cellulose as a Potential Binder for HardCarbon Negative Electrodes in Sodium-Ion Batteries. Electrochem. Commun. 2014, 44, 66-69.

(4) Luo, C.; Du, L.; Wu, W.; Xu, H.; Zhang, G.; Li, S.; Wang, C.; Lu, Z.; Deng, Y. Novel Lignin-Derived Water-Soluble Binder for Micro Silicon Anode in Lithium-Ion Batteries. ACS Sustainable Chem. Eng. 2018, 6, 12621-12629.

(5) Domínguez-Robles, J.; Sánchez, R.; Díaz-Carrasco, P.; Espinosa, E.; García-Domínguez, M. T.; Rodríguez, A. Isolation and Characterization of Lignins from Wheat Straw: Application as Binder in Lithium Batteries. Int. J. Biol. Macromol. 2017, 104, 909-918.

(6) Courtel, F. M.; Niketic, S.; Duguay, D.; Abu-lebdeh, Y.; Davidson, I. J. Water-Soluble Binders for MCMB Carbon Anodes for Lithium-Ion Batteries. J. Power Sources 2011, 196, 2128-2134.

(7) An, Y.; Feng, J.; Ci, L.; Xiong, S. MnO2 Nanotubes with a Water Soluble Binder as High Performance Sodium Storage Materials. RSC Adv. 2016, 6, 103579-103584.

(8) Larcher, D.; Tarascon, J. M. Towards Greener and More Sustainable Batteries for Electrical Energy Storage. Nat. Chem. 2015, 7, 19-29.

(9) Muñoz-Márquez, M. Á.; Saurel, D.; Gómez-Cámer, J. L.; CasasCabanas, M.; Castillo-Martínez, E.; Rojo, T. Na-Ion Batteries for Large Scale Applications: A Review on Anode Materials and Solid Electrolyte Interphase Formation. Adv. Energy Mater. 2017, 7, 1700463.

(10) Vaalma, C.; Buchholz, D.; Weil, M.; Passerini, S. A cost and resource analysis of sodium-ion batteries. Nat. Rev. Mater. 2018, 3, 18013.

(11) Hosaka, T.; Kubota, K.; Hameed, A. S.; Komaba, S. Research Development on K-Ion Batteries. Chem. Rev. 2020, 120, 6358-6466.

(12) Liu, Q.; Hu, Z.; Chen, M.; Zou, C.; Jin, H.; Wang, S.; Chou, S. L.; Liu, Y., Dou, S. X.; Dou, S. X. The Cathode Choice for Commercialization of Sodium-Ion Batteries: Layered Transition Metal Oxides versus Prussian Blue Analogs. Advanced Functional Materials. Wiley-VCH Verlag April 2020, p 1909530. DOI DOI: 10.1002/adfm.201909530.

(13) Barpanda, P.; Lander, L.; Nishimura, S. I., Yamada, A.; Yamada, A. Polyanionic Insertion Materials for Sodium-Ion Batteries. Advanced Energy Materials; Wiley-VCH Verlag June: 2018, p 1703055. DOI DOI: 10.1002/aenm.201703055.

(14) Zhao, Q.; Lu, Y., Chen, J.; Chen, J. Advanced Organic Electrode Materials for Rechargeable Sodium-Ion Batteries. Advanced Energy Materials; Wiley-VCH Verlag April: 2017, p 1601792. DOI DOI: $10.1002 /$ aenm.201601792.

(15) Wang, L.; Song, J.; Qiao, R.; Wray, L. A.; Hossain, M. A.; Chuang, Y.-D.; Yang, W.; Lu, Y.; Evans, D.; Lee, J. J.; Vail, S.; Zhao, X.; Nishijima, M.; Kakimoto, S.; Goodenough, J. B. Rhombohedral Prussian White as Cathode for Rechargeable Sodium-Ion Batteries. J. Am. Chem. Soc. 2015, 137, 2548-2554.

(16) Dahbi, M.; Yabuuchi, N.; Kubota, K.; Tokiwa, K.; Komaba, S. Negative Electrodes for Na-Ion Batteries. Phys. Chem. Chem. Phys. 2014, 16, 15007.

(17) Luo, W.; Shen, F.; Bommier, C.; Zhu, H.; Ji, X.; Hu, L. Na-Ion Battery Anodes: Materials and Electrochemistry. Acc. Chem. Res. 2016, 49, 231-240.

(18) Irisarri, E.; Ponrouch, A.; Palacin, M. R. Review-Hard Carbon Negative Electrode Materials for Sodium-Ion Batteries. J. Electrochem. Soc. 2015, 162, A2476-A2482. 
(19) Li, Z.; Jian, Z.; Wang, X.; Rodríguez-Pérez, I. A.; Bommier, C.; Ji, X. Hard Carbon Anodes of Sodium-Ion Batteries: Undervalued Rate Capability. Chem. Commun. 2017, 53, 2610-2613.

(20) Xiao, B.; Rojo, T.; Li, X. Hard Carbon as Sodium-Ion Battery Anodes: Progress and Challenges. ChemSusChem 2019, 12, 133-144. (21) Asfaw, H. D.; Tai, C. W.; Valvo, M.; Younesi, R. Facile Synthesis of Hard Carbon Microspheres from Polyphenols for Sodium-Ion Batteries: Insight into Local Structure and Interfacial Kinetics. Mater. Today Energy 2020, 18, 100505.

(22) Chen, X.; Zheng, Y.; Liu, W.; Zhang, C.; Li, S.; Li, J. HighPerformance Sodium-Ion Batteries with a Hard Carbon Anode: Transition from the Half-Cell to Full-Cell Perspective. 2019, 11 (46), 22196-22205, DOI: 10.1039/c9nr07545c.

(23) Dou, X.; Hasa, I.; Hekmatfar, M.; Diemant, T.; Behm, R. J.; Buchholz, D.; Passerini, S. Pectin, Hemicellulose, or Lignin? Impact of the Biowaste Source on the Performance of Hard Carbons for Sodium-Ion Batteries. ChemSusChem 2017, 10, 2668-2676.

(24) Shen, Y.; Sun, S.; Yang, M.; Zhao, X. Typha-Derived Hard Carbon for High-Performance Sodium Ion Storage. J. Alloys Compd. 2019, 784, 1290-1296.

(25) Xiao, L.; Lu, H.; Fang, Y.; Sushko, M. L.; Cao, Y.; Ai, X.; Yang, H.; Liu, J. Low-Defect and Low-Porosity Hard Carbon with High Coulombic Efficiency and High Capacity for Practical Sodium Ion Battery Anode. Adv. Energy Mater. 2018, 8, 1703238.

(26) Jean, J. H.; Wang, H. R. Organic Distributions in Dried Alumina Green Tape. J. Am. Ceram. Soc. 2001, 84, 267-272.

(27) Chou, S. L.; Pan, Y.; Wang, J. Z.; Liu, H. K.; Dou, S. X. Small Things Make a Big Difference: Binder Effects on the Performance of $\mathrm{Li}$ and Na Batteries. Phys. Chem. Chem. Phys. 2014, 16, 20347-20359.

(28) Bommier, C.; Ji, X. Electrolytes, SEI Formation, and Binders: A Review of Nonelectrode Factors for Sodium-Ion Battery Anodes. Small 2018, 14, 1703576.

(29) Young, B. T.; Nguyen, C. C.; Lobach, A.; Heskett, D. R.; Woicik, J. C.; Lucht, B. L. Role of Binders in Solid Electrolyte Interphase Formation in Lithium Ion Batteries Studied with Hard XRay Photoelectron Spectroscopy. J. Mater. Res. 2019, 34, 97-106.

(30) Li, Z.; Bommier, C.; Chong, Z.; Jian, Z.; Surta, T. W.; Wang, X.; Xing, Z.; Neuefeind, J. C.; Stickle, W. F.; Dolgos, M.; Greaney, P. A.; Ji, X.; Sen; Jian, Z.; Surta, T. W.; Wang, X.; Xing, Z.; Neuefeind, J. C.; Stickle, W. F.; Dolgos, M.; Greaney, P. A.; Ji, X. Mechanism of NaIon Storage in Hard Carbon Anodes Revealed by Heteroatom Doping. Adv. Energy Mater. 2017, 7, 1-10.

(31) Komaba, S.; Murata, W.; Ishikawa, T.; Yabuuchi, N.; Ozeki, T.; Nakayama, T.; Ogata, A.; Gotoh, K.; Fujiwara, K. Electrochemical Na Insertion and Solid Electrolyte Interphase for Hard-Carbon Electrodes and Application to Na-Ion Batteries. Adv. Funct. Mater. 2011, 21, 3859-3867.

(32) Alvin, S.; Yoon, D.; Chandra, C.; Cahyadi, H. S.; Park, J. H.; Chang, W.; Chung, K. Y.; Kim, J. Revealing Sodium Ion Storage Mechanism in Hard Carbon. Carbon N. Y. 2019, 145, 67-81.

(33) Eshetu, G. G.; Elia, G. A.; Armand, M.; Forsyth, M.; Komaba, S.; Rojo, T.; Passerini, S. Electrolytes and Interphases in SodiumBased Rechargeable Batteries: Recent Advances and Perspectives. Adv. Energy Mater. 2020, 10, 2000093.

(34) Peled, E.; Menkin, S. Review-SEI: Past, Present and Future. J. Electrochem. Soc. 2017, 164, A1703-A1719.

(35) Song, J.; Xiao, B.; Lin, Y.; Xu, K.; Li, X. Interphases in SodiumIon Batteries. Adv. Energy Mater. 2018, 8, 1-24.

(36) Schmitz, R. W.; Murmann, P.; Schmitz, R.; Müller, R.; Krämer, L.; Kasnatscheew, J.; Isken, P.; Niehoff, P.; Nowak, S.; Röschenthaler, G. V.; Ignatiev, N.; Sartori, P.; Passerini, S.; Kunze, M.; Lex-Balducci, A.; Schreiner, C.; Cekic-Laskovic, I.; Winter, M. Investigations on Novel Electrolytes, Solvents and SEI Additives for Use in Lithium-Ion Batteries: Systematic Electrochemical Characterization and Detailed Analysis by Spectroscopic Methods. Prog. Solid State Chem. 2014, 42, 65-84.

(37) Komaba, S. Sodium-Driven Rechargeable Batteries: An Effort towards Future Energy Storage. Chem. Lett. 2020, 49, 1507-1516.
(38) Ferrari, A. C.; Robertson, J. Interpretation of Raman Spectra of Disordered and Amorphous Carbon. Phys. Rev. B 2000, 61, 1409514107.

(39) Wang, R.; Feng, L.; Yang, W.; Zhang, Y.; Zhang, Y.; Bai, W.; Liu, B.; Zhang, W.; Chuan, Y.; Zhang, Z.; Guan, H. Effect of Different Binders on the Electrochemical Performance of Metal Oxide Anode for Lithium-Ion Batteries. Nanoscale Res. Lett. 2017, 12, 575.

(40) Ohta, N.; Sogabe, T.; Kuroda, K. A Novel Binder for the Graphite Anode of Rechargeable Lithium Ion Batteries for the Improvement of Reversible Capacity [5]. Carbon N. Y. 2001, 39, 1434-1436.

(41) Iermakova, D. I.; Dugas, R.; Palacín, M. R.; Ponrouch, A. On the Comparative Stability of $\mathrm{Li}$ and $\mathrm{Na}$ Metal Anode Interfaces in Conventional Alkyl Carbonate Electrolytes. J. Electrochem. Soc. 2015, 162, A7060-A7066.

(42) Buqa, H.; Holzapfel, M.; Krumeich, F.; Veit, C.; Novák, P. Study of Styrene Butadiene Rubber and Sodium Methyl Cellulose as Binder for Negative Electrodes in Lithium-Ion Batteries. J. Power Sources 2006, 161, 617-622.

(43) Seki, S.; Tabata, S. I.; Matsui, S.; Watanabe, M. Effect of Binder Polymer Structures Used in Composite Cathodes on Interfacial Charge Transfer Processes in Lithium Polymer Batteries. Electrochim. Acta 2004, 50, 379-383.

(44) El Ouatani, L.; Dedryvère, R.; Ledeuil, J. B.; Siret, C.; Biensan, P.; Desbrières, J.; Gonbeau, D. Surface Film Formation on a Carbonaceous Electrode: Influence of the Binder Chemistry. J. Power Sources 2009, 189, 72-80.

(45) Painter, L. R.; Arakawa, E. T.; Williams, M. W.; Ashley, J. C. Optical Properties of Polyethylene: Measurement and Applications. Radiat. Res. 1980, 83, 1.

(46) Powell, C. J.; Jablonski, A. NIST Electron Inelastic-Mean-FreePath Database, Version 1.2, SRD 71; National Institute of Standards and Technology: Gaithersburg, MD, 2010. DOI DOI: 10.18434/ T48C78.

(47) Wang, J.; Yamada, Y.; Sodeyama, K.; Watanabe, E.; Takada, K.; Tateyama, Y.; Yamada, A. Fire-Extinguishing Organic Electrolytes for Safe Batteries. Nat. Energy 2018, 3, 22-29.

(48) Carboni, M.; Manzi, J.; Armstrong, A. R.; Billaud, J.; Brutti, S.; Younesi, R.; Younesi, R. Analysis of the Solid Electrolyte Interphase on Hard Carbon Electrodes in Sodium-Ion Batteries. ChemElectroChem 2019, 1745-1753.

(49) Edström, K.; Herstedt, M.; Abraham, D. P. A New Look at the Solid Electrolyte Interphase on Graphite Anodes in Li-Ion Batteries. J. Power Sources 2006, 153, 380-384.

(50) Mogensen, R.; Brandell, D.; Younesi, R. Solubility of the Solid Electrolyte Interphase (SEI) in Sodium Ion Batteries. ACS Energy Lett. 2016, 1, 1173-1178. 